OUR ASTRONOMICAL COLUMN.

Brilliant Meteor of October $7 .-\Lambda$ very fine meteor, which illuminated the heavens like a flash of lightning, was observed at various places in the west of England on October 7 at 10.35 p.m. It was seen by Mr. I. T. Naish at Bishopston, Btistol, and he rec rded the position of the streak, which endured for nearly half a minute, as from $337^{\circ}+8^{\circ}$ to $327^{\circ}-2^{\circ}$. As observed by Miss Eleonora Armitage at Swainswick, near Bath, the meteor is described as coming rapidly from overhead and disappearing in Aquila. It left a luminous trail about $10^{\circ}$ long, lasting for a few secunds.

M[r. F. C. Carey, of H.M.S. Illustrious, Devonport, noticed a lightning-like flash, and on looking upwards saw in due east, altitude $60^{\circ}$, a luminous train which was brighter in the upper portion and remained visible for several seconds.

The meteor was also visible from Keynsham, near Bristol, and by several other observers at Bristol.

From the data collected by Mr. Denning, he finds that the meteor had a probable radiant in Gemini, and that its height was from about seventy-four to fifty-two miles. The position of the flight was from over Wiltshire to the English Channel, about ten miles east of Paignton, Devonshire. Further observations are needed of a more exact character to determine its real path accurately. The meteor was a very swift one of the Leonid type, and it appeared on a very unsettled, showery evening, when, unfortunately, the sky was cloudy at many places.

('OMETary OBSERvations IN IgO9 TO IgI2.-The principal contents of No. I2 of the Mitteilungen der Hamburger Sterwarte relate to the observations made of comets which appeared in the interval included in the years 1909 to I912. The observations there recorded are both visual and photographic, the former being made with an equatorial of $25^{6} \mathrm{~mm}$. aperture and $3.02 \mathrm{~m}$. focal length, and the latter with a ${ }_{1} 5^{8} \mathrm{~mm}$. Petzval objective of $760 \mathrm{~mm}$. focal length, and a 5 -in. Cooke triplet of $600 \mathrm{~mm}$. focal length. Dr. K. Graff gives an account of the physical observations made with the large equatorial, and accompanies his remarks with an excellent series of drawings of the detailed structures in the heads of the various comets observed. Prof. A. Schwassmann limits his account to Brooks's comet (IgI I $C$ ), and describes in detail the chief points which are noticeable on the fine series of photographs which accompany the text. This publication also includes the observations made for the determinations of the positions of the comets and numerous minor planets, all made with the large equatorial by the observers, Dr. K. F. Bottlinger, Dr. K. Graff, and Herr H. Thiele.

Normal System of Wave-lenglhs in the Spectioum OF THE IRON ARc.--In this column for October 2 reference was made under the heading "The Wave-

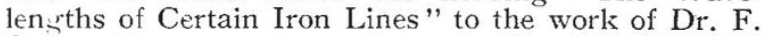
Gois. The current number of The Astrophysical Journal (vol. xxxviii., No. 2, p. I4I) contains a further contribution by him towards "the establishment of a normal system of wave-lengths in the arc spectrum of iron." The main object of the communication is to show that it is not sufficient to prescribe a current of $\vec{s}$ to io amperes for the arc, as was adopted by the International Solar Union, but that it is absolutely necessary to define the manner of burning and the part of the arc used. Dr. Goos recommends the following procedure, based on many experiments :-

For the normal spectrum of iron he proposes an $\operatorname{arc} 5 \mathrm{~mm}$. long (separation of the rounded ends from each other) between iron rods $6 \mathrm{~mm}$. in diameter and with a current of 4 amperes. It should be used on a 220-volt circuit; the potential difference at the arc then falls to between 45 and 49 volts. It should be used with a pole changer, and the arc so projected on the slit of the spectrograph with the condensing lens that only a portion of the arc at the middle is used extending $\mathrm{I} .5 \mathrm{~mm}$. vertically at most. In order to show the importance of specifying exactly the arc conditions to be used, he directs attention to the difference in the values of the three observers of the normals of the second order. Thus he compares the wave-lengths of the iron arc as published by Kayser and himself with the measurements of St. John and Ware. He also includes measurements of the widths of some selected iron lines. The main cause of all the differences is due to pressure changes, and the whole investigation shows that the iron arc is far from homogeneous. Dr. Goos finally questions whether the measurements of the normals of the third order form a really homogeneous system, and he proposes that an entirely new series of observations should be made with more uniform light-sources.

\section{MICROSCOPICAL EXAMINATION OF SKIN AND LEATHER.}

$\mathrm{I}$ the May number of the Bulletin de la Societé d'Encouragement pour l'Industrie Nationale, M. Georges Abt, of the Pasteur Institute, contributes an interesting and valuable paper on the microscopical examination of skin and leather, with special reference to salt stains and their effect.

The author first describes in detail the methods used for cutting and staining sections of skin. These are the general methods familiar to microscopists, but are varied slightly in order to differentiate the important histological elements of the skin for the particular purpose in view. The author endeavours to classify the different changes taking place in the skin during the various processes of manufacture into leather, and even goes so far as to suggest that the microscopical examination of the skin or hide in the various stages might be used to control the various processes.

In connection with his special investigation, the effect of salt stains, the author has prepared sections of the grain, flesh, and interior of the raw skin, the pelt, and of the finished leather, showing the characteristics of salt stains and their effect.

The work is supplementary, and supports the hypothesis deduced by the same writer from a chemical investigation of these stains ("Collegium," I912, pp. 388-408). M. Abt differentiates between two types of salt stains. Stains of the first class are distinguished by the presence of calcium phosphate in places where grains of calcium sulphate have been deposited from the salt. In the section through these stains the nuclei of the connective tissue are very prominent. The author has proved them to contain iron and excess of tannin in the sections of stained leather. He assumes that these nuclei have been protected from the destructive action of micro-organisms in the preliminary processes by an envelope of an organic iron salt and of iron and calcium phosphate, and he goes on to show that as the salt stain progresses the nuclei ultimately disappear, the connective tissues being disintegrated, but not completely decomposed, as they would be by the action of bacteria, as claimed by Becker.

The second kind of stain investigated only applied to horse hides and to leather made therefrom. These are characterised bv the presence of strongly pigmented epithelial tissues and the complete absence of calcium phosphate. The writer assum $s_{2}$ therefore,

NO. 2294, VOL. 92] 